\title{
Public involvement in the design and conduct of clinical trials: a narrative review of case examples
}

\author{
Jonathan Boote ${ }^{1 *}$, Wendy Baird', Anthea Sutton ${ }^{2}$ \\ From Clinical Trials Methodology Conference 2011 \\ Bristol, UK. 4-5 October 2011
}

\section{Background}

Public involvement is health research policy in the UK and internationally. There is a need to establish a robust evidence base on the impact of public involvement on research processes and outcomes.

\section{Aim}

To review case examples of public involvement in the design and conduct of clinical trials, to synthesise the contributions of the public, as well as the identified tensions and facilitating strategies.

\section{Method}

Systematic literature search and narrative review.

\section{Findings}

Nine papers were identified, covering the following topics: breast-feeding, antiretroviral and nutrition interventions [1]; paediatric resuscitation [2]; exercise and cognitive behavioural therapy [3]; hormone replacement therapy and breast cancer [4]; stroke [5,6]; chronic suppurative otitis media [7]; Paget's disease [8]; and shared decision-making in patient consultations [9]. Six papers reported on public involvement at the trial design stage, while three reported on public involvement at the design and conduct stages of clinical trials. It was found that the public contributed at the consultation, collaboration and publicly-led levels of involvement. Four main public contributions to trial design were identified: review of consent procedures and patient information sheets; suggestion of additional trial outcomes; review of trial data collection procedures; and recommendations on the timing and location of trial follow-up data

\footnotetext{
* Correspondence: j.boote@sheffield.ac.uk

'NIHR Research Design Service for Yorkshire and the Humber, South

Yorkshire, S1 4DA, UK

Full list of author information is available at the end of the article
}

collection. Two main contributions that the public made to the conduct of trials were identified: scrutiny of the conduct of the trial through membership of the Trial Steering Committee; and delivering the trial protocol after completing relevant training. Four main tensions were identified with regard to involving the public in trial design and conduct: tensions between stakeholder groups when designing trials; public understanding of trial methodology; the added time, complexity and cost of public involvement; and the representativeness of the public involved. Four main facilitating strategies were identified with regard to involving the public in trial design and conduct: cultural sensitivity; clear explanation of trial methodology; independent facilitation of trial design planning meetings; and adequate funding for public involvement.

\section{Limitations}

Papers on public involvement in the design and conduct of clinical trials may have been overlooked due to the difficulty of searching for, and identifying, papers in this area. Only publications published in English were searched for and the review focused on evidence contained in peer-reviewed journal articles only.

\section{Conclusions}

The issues raised in this review should assist researchers in developing and conducting clinical trials with the involvement of the public.

\section{Author details \\ ${ }^{1}$ NIHR Research Design Service for Yorkshire and the Humber, South Yorkshire, S1 4DA, UK. ${ }^{2}$ School of Health and Related Research, University of Sheffield, South Yorkshire, S1 4DA, UK.}

Published: 13 December 2011

(c) 2011 Boote et al; licensee BioMed Central Ltd. This is an open access article distributed under the terms of the Creative Commons 


\section{References}

1. Corneli AL, Piwoz EG, Bentley ME, Moses A, Nkhoma JR, Tohill BC, et al: Involving communities in the design of clinical trial protocols: the BAN Study in Lilongwe, Malawi. Contemporary Clinical Trials 2007, 28:59-67.

2. Morris MC, Nadkarni VM, Ward FR, Nelson RM: Exception from informed consent for pediatric resuscitation research: community consultation for a trial of brain cooling after in-hospital cardiac arrest. Pediatrics 2004, 114:776-81.

3. Guarino P, Elbourne D, Carpenter J, Peduzzi P: Consumer involvement in consent document development: a multicenter cluster randomized tria to assess study participants' understanding. Clinical Trials 2006, 3:19-30.

4. Marsden J, Bradburn J: Patient and clinician collaboration in the design of a national randomized breast cancer trial. Health Expectations 2004, 7:6-17.

5. Koops L, Lindley RI: Thrombolysis for acute ischaemic stroke: consumer involvement in the design of new randomised controlled trial. BMJ 2002, 325:415-7.

6. Ali K, Roffe C, Crome P: What patients want: consumer involvement in the design of a randomised controlled trial of routine oxygen supplementation after acute stroke. Stroke 2006, 37:865-71.

7. Couzos S, Lea T, Murray R, Culbong M: 'We are not just participants-we are in charge': the NACCHO ear trial and the process for Aboriginal community-controlled health research. Ethnicity \& Health 2005, 10:91-111.

8. Langston AL, McCallum M, Campbell MK, Robertson C, Ralston SH: An integrated approach to consumer representation and involvement in a multicentre randomized controlled trial. Clinical Trials 2005, 2:80-87.

9. Thornton H, Edwards A, Elwyn G: Evolving the multiple roles of 'patients' in health-care research: reflections after involvement in a trial of shared decision-making. Health Expectations 2003, 6:189-189.

doi:10.1186/1745-6215-12-S1-A82

Cite this article as: Boote et al: Public involvement in the design and conduct of clinical trials: a narrative review of case examples. Trials 2011 12(Suppl 1):A82.

\section{Submit your next manuscript to BioMed Central and take full advantage of:}

- Convenient online submission

- Thorough peer review

- No space constraints or color figure charges

- Immediate publication on acceptance

- Inclusion in PubMed, CAS, Scopus and Google Scholar

- Research which is freely available for redistribution

Submit your manuscript at www.biomedcentral.com/submit
Biomed Central 